\title{
Hystererectomy in a Tertiary Hospital in a Sub-Saharan Setting: A 20-Year Retrospective Review of the Indications, Types and Analysis of Technical Index
}

\author{
Théophile Njamen Nana1,2, Robert Tchounzou ${ }^{2,3 *}$, Fulbert Nkwele Mangala1,4, Henri Essome ${ }^{4,5}$, \\ Fidelia Mbi Kobenge1, Bongoe Adamo1, Gregory Ekane Halle',2, Thomas Obinchemti Egbe1,2, \\ Charlotte Tchente Nguefack ${ }^{1,4}$
}

\begin{abstract}
${ }^{1}$ Department of Obstetrics and Gynecology, Douala General Hospital, Douala, Cameroon
${ }^{2}$ Department of Obstetrics and Gynecology, Faculty of Health Sciences, University of Buea, Buea, Cameroon

${ }^{3}$ Department of Obstetrics and Gynecology, Douala Gynaeco-Obstetrics and Paediatric Hospital, Douala, Cameroon

${ }^{4}$ Department of Surgery and Specialities, Faculty of Medicine and Pharmaceutical Sciences, University of Douala, Douala, Cameroon

${ }^{5}$ Department of Obstetrics and Gynecology, Douala Laquintinie Hospital, Douala, Cameroon

Email: *rtchounzou@yahoo.fr
\end{abstract}

How to cite this paper: Nana, T.N., Tchounzou, R., Mangala, F.N., Essome, H., Kobenge, F.M., Adamo, B., Halle, G.E., Egbe, T.O. and Nguefack, C.T. (2021) Hystererectomy in a Tertiary Hospital in a Sub-Saharan Setting: A 20-Year Retrospective Review of the Indications, Types and Analysis of Technical Index. Open Journal of Obstetrics and Gynecology, 11, 885-897. https://doi.org/10.4236/ojog.2021.117083

Received: April 15, 2021

Accepted: July 18, 2021

Published: July 21, 2021

Copyright $\odot 2021$ by author(s) and Scientific Research Publishing Inc. This work is licensed under the Creative Commons Attribution International License (CC BY 4.0).

http://creativecommons.org/licenses/by/4.0/ (c) (i) Open Access

\begin{abstract}
Background: Hysterectomy is one of the most performed surgeries through the world, even in Sub Saharan setting where indications are not rare. Objective: To study the frequency, indications, surgical methods, and complications of hysterectomies at the Douala General Hospital. Patients and methods: We carried out a cross-sectional study over a 20 -year period, from the $1^{\text {st }}$ January 2000 to $31^{\text {st }}$ December 2019, in the department of Gynaecology and Obstetrics of the Douala General Hospital, a tertiary health facility in Cameroon, central Africa. All patients who underwent hysterectomies for gynaecological or obstetrical indications and whose files were complete were retained. Results: Out of a total of 7126 gynaecological and obstetrical surgical cases 1007 were hysterectomies, giving a frequency of $14.21 \%$. Meanwhile, 968 files fulfilled the inclusion criteria. The average age of the patients was $45.75 \pm 7.71$ years (range 19 to 75 years). The indications included symptomatic fibroids $64.15 \%$ (621 cases), gynaecological cancers $13.94 \%$ (135 cases), severe cervical dysplasia $11.15 \%$ (108 cases), and endometrial hyperplasia with atypia $7.02 \%$ (68 cases), haemostatic hysterectomies $2.68 \%$ (26 cases), uterine prolapse $0.82 \%$ ( 8 cases), a case of post abortion uterine necrosis $(0.10 \%)$ and a case of uterine endometriosis $(0.10 \%)$. Laparotomy was the main surgical approach $86.05 \%$ (833 cases), followed by the vaginal route, $10.20 \%$ (97 cases) and then laparoscopy $3.92 \%$ (38 cases). The average length
\end{abstract}


of hospital stay was $6.07 \pm 1.92$ days following laparotomy, $3 \pm 1.09$ days following the vaginal route, and $3.6 \pm 1.04$ days following laparoscopy. The main intra-operative complications included haemorrhage, $1.75 \%$ (17 cases), bladder injuries $0.82 \%$ ( 8 cases) and ureteral injuries $0.72 \%$ (7 patients). Post-operative complications mainly included: fever 3.61\% (35 cases), anaemia $2.5 \%$ (24 cases) and abdominal wall sepsis $0.92 \%$ (9 cases). Conclusion: The frequency of hysterectomy was $14.21 \%$. Uterine fibroid, gynaecological cancer and cervical dysplasia were the main indications. Intra-operative haemorrhage, bladder and ureteral injuries were the major complications. Increase in the practice of vaginal and laparoscopic hysterectomies could contribute to the reduction of peri and post-operative complications and hospital stay. Thus reinforcement of abilities is required.

\section{Keywords}

Hysterectomy, Indications, Surgical Methods, Complications, Douala General Hospital-Cameroon

\section{Introduction}

Hysterectomy is amongst the most performed surgical interventions in Gynaecology [1]. This surgical intervention is usually done for benign pathologies like uterine fibroids and is reported to represent up to $20 \%$ of gynaecological interventions in some countries [1] [2]. The main indications of hysterectomies reported in the literature are benign pathologies of uterus like leiomyomas [1] [2] [3]. For a long time, abdominal hysterectomy has remained the main type followed by vaginal route especially in developing countries. Buambo et al. in a retrospective study done in Brazzaville found that abdominal route was the main route $(82.5 \%)$ followed by vaginal route (17.5\%) [3]. Development and popularisation of minimally invasive approaches and alternatives like endometrectomy in recent years have enabled the reduction of complications, morbidity and hospital stay linked to abdominal approach. The trend in the recent years, in developed countries, has been to use minimally invasive techniques both for benign and malignant uterine diseases [4] [5]. The first laparoscopic hysterectomy is reported to have been performed in 1989 and demonstrated several advantages as compared to the traditional abdominal route like less post-operative pains, better cosmetics, shorter hospital stay, early recovery time [4] [5] [6] and [7]. Laparoscopic and vaginal routes are now the standard over the abdominal route whenever possible in western countries [4] [5] as compared to Subsaharan settings where vaginal and laparoscopic routes are seldom performed [3]. Many authors think that the technical index of hysterectomy is an indicator of the quality of gynaecological service. Mindful of this, in a bit to improve in our practice, we designed this study to audit the practice of hysterectomies for obstetrical and gynaecological reasons in our service with regards to the frequency, 
the indications, the types and to take stock of our technical index.

\section{Material and Methods}

\subsection{Study Design, Period and Site}

We carried out a cross-sectional retrospective study, in the department of Obstetrics and Gynaecology of the Douala General Hospital (DGH), from the $1^{\text {st }}$ January 2000 to $31^{\text {st }}$ December 2019, in order to assess the frequency, indications, surgical methods and complications of hysterectomy.

The DGH is a tertiary health structure in Douala, the largest city and economical capital of Cameroon, with an estimated population of over three million inhabitants. This hospital has a capacity of 320 beds and hosts many services, amongst which is the service of Obstetrics and Gynaecology. The workforce of the Gynecology and Obstetrics department is constituted of 8 gynaecologist and Obstetricians, with few having special training in vaginal surgery, Laparoscopy and other surgical techniques. The service is involved in the training of medical students and resident doctors in Obstetric and Gynecology.

\subsection{Inclusion and Exclusion Criteria}

Patients included were those who have undergone hysterectomy for gynaecological or obstetrical indications, in the service of Obstetrics and Gynaecology of the DGH, and whose files were complete. A file was considered complete if it contains beside others at least the following information: age, the indication, the route of surgery, the duration of hospital stay, and the outcome of management. Files with more than $25 \%$ (more than one these key data) of missing data were excluded from the study.

\subsection{Data Collection}

A list of patients who underwent hysterectomy was obtained from the theatre and inpatients registers. The files of the patients were then compiled and information was retrieved and filled in a pre-established data collection form. The data recorded included the age, surgical indication, surgical method, intra and post-operative complications and the length of hospital stay. Blood loss of more than $500 \mathrm{ml}$ was considered as hemorrhagic complications. Febrile morbidity was considered for a postoperative temperature of above $38^{\circ} \mathrm{C}$.

\subsection{Statistical Analysis of Data}

The data were typed and analysed using the software SPSS 21.0 version. The results were reported in terms of number, mean, and percentage. The differences between the groups were determined with the Fisher's test with $\mathrm{p} \leq 0.05$.

\subsection{Ethical Considerations}

The study was endorsed by the national ethical committee. Access to files was granted only after approval from the ethical committee of the institution. The 
data were exploited discreetly.

\section{Results}

968 files fulfilled inclusion criteria and were enrolled in this study. The sociodemographic characteristics, the frequency, the indications of the surgery, the route of surgery, the hospital stay, and the complications are summarized in Table 1.

\subsection{Age}

The mean age of the patients was $45.75 \pm 7.71$ years (extremes 19 to 75 years). The age range of 40 to 50 years was the most represented 56.40\%: (546 cases) (Table 2).

\subsection{Frequency}

Out of 7126 surgical cases realised in the service, 1007 patients underwent an

Table 1. Frequency of hysterectomies at Douala General Hospital from 2000 to 2019.

\begin{tabular}{|c|c|c|c|}
\hline Year & $\begin{array}{l}\text { Number of cases of } \\
\text { hysterectomies }\end{array}$ & $\begin{array}{l}\text { Number of gynecological } \\
\text { surgery cases }\end{array}$ & $\begin{array}{c}\text { Frequency of } \\
\text { hysterectomies in \% }\end{array}$ \\
\hline 2000 & 35 & 288 & 12.15 \\
\hline 2001 & 37 & 298 & 12.41 \\
\hline 2002 & 36 & 263 & 13.68 \\
\hline 2003 & 56 & 345 & 16.23 \\
\hline 2004 & 52 & 352 & 14.77 \\
\hline 2005 & 47 & 312 & 15.06 \\
\hline 2006 & 49 & 302 & 16.22 \\
\hline 2007 & 44 & 280 & 15.71 \\
\hline 2008 & 42 & 276 & 15.21 \\
\hline 2009 & 40 & 296 & 13.51 \\
\hline 2010 & 65 & 425 & 15.29 \\
\hline 2011 & 62 & 427 & 14.51 \\
\hline 2012 & 58 & 471 & 12.31 \\
\hline 2013 & 55 & 430 & 12.79 \\
\hline 2014 & 55 & 418 & 13.15 \\
\hline 2015 & 44 & 258 & 17.05 \\
\hline 2016 & 58 & 424 & 13.67 \\
\hline 2017 & 55 & 410 & 13.41 \\
\hline 2018 & 61 & 428 & 14.25 \\
\hline 2019 & 56 & 423 & 13.23 \\
\hline Total & 1007 & 7126 & 14.21 \\
\hline
\end{tabular}

1007 cases of hysterectomies were performed. It represented $14.21 \%$ of surgical operations, hence an average of 43.8 cases per year. 
Table 2. Distribution of hysterectomies by age.

\begin{tabular}{ccc}
\hline Age group (year) & Number (n) & Percentage (\%) \\
\hline $40-50$ & 546 & 56.45 \\
$>50$ & 306 & 31.63 \\
$30-40$ & 101 & 10.35 \\
$<30$ & 15 & 1.56 \\
Total & 968 & 100 \\
\hline
\end{tabular}

The mean age of the patients was $45.76 \pm 7.71$ years with a minimum of 19 years and a maximum of 75 years. Patients over 40 years old were the most represented.

hysterectomy, giving a frequency of $14.21 \%$. Thirty-nine incomplete files were excluded and our study involved 968 patients.

\subsection{Indications}

The indications included symptomatic fibroids $64.15 \%$ (621 cases), gynaecological cancers $13.94 \%$ (135 cases), severe cervical dysplasia $11.15 \%$ (108 cases), and endometrial hyperplasia with atypia $7.02 \%$ (68 cases), haemostatic hysterectomies 2 , $68 \%$ ( 26 cases), uterine prolapse $0.82 \%$ ( 8 cases), one case of post abortion uterine necrosis $(0.10 \%)$ and one case of uterine endometriosis $(0.10 \%)$ (Table 3$)$. Total hysterectomy was performed during debulking surgery in 76 cases of ovarian cancers while 53 cases included expanded hysterectomies for cervical cancer. Subtotal hysterectomy was performed for 1 case of post abortion uterine necrosis and in 4 cases of debulking surgery for frozen pelvis.

\subsection{Surgical Method}

Laparotomy was the main surgical type $85.95 \%$ ( 832 cases), followed by the vaginal route $10.20 \%$ (97 cases) and laparoscopy $3.92 \%$ (38 cases). All the laparoscopic hysterectomies were total, and involved benign uterine pathologies in patients without a history of prior abdomino-pelvic surgery and in whom the uterine size did not exceed 12 weeks of amenorrhea. Fourty percent of laparoscopic hysterectomies performed were type II according to "classification of Mage" [2] (Table 4).

\subsection{Duration of Hospital Stay}

The average length of hospital stay was $6.07 \pm 1.92$ days following laparotomy, $3 \pm$ 1.09 days following the vaginal route, and $3.6 \pm 1.04$ days following laparoscopy. Of the three surgical methods, the length of hospital stay was longer following abdominal hysterectomy with a significant difference $(p=0.00023)$ (Table 5).

\subsection{Complications}

We found a global rate of complications of $11 \%$ (106 cases), with $3.5 \%$ (34 cases) intra-operatively and 7.5\% (72 cases) postoperatively (Table 6).

Intra-operative complications included haemorrhage, 1.75\% (17 cases), bladder 
Table 3. Distribution of hysterectomies according to indications $(n=968)$.

\begin{tabular}{ccc}
\hline Indications & Number (n) & Percentage (\%) \\
\hline Symptomatic fibroids & 621 & 64.15 \\
Gynecological Cancer & 135 & 13.94 \\
Severe cervical dysplasia (SIL II) & 108 & 11.15 \\
Atypical hyperplasia of the endometrium & 68 & 7.02 \\
Haemostastic hysterectomy & 26 & 2.68 \\
Uterine Prolapse & 8 & 0.82 \\
Endometriosis & 1 & 0.10 \\
Perforation with uterine necrosis & 1 & 0.10 \\
Total & 968 & 100 \\
\hline
\end{tabular}

Symptomatic myomas, severe cervical dysplasia and cervical cancer were the main indications in order of importance.

Table 4. Hysterectomies and surgical methods.

\begin{tabular}{ccc}
\hline Surgical methods & Number (n) & Percentage (\%) \\
\hline Laparotomy & 833 & 86.05 \\
Vaginal route & 97 & 10.02 \\
Laparoscopy & 38 & 3.92 \\
Total & 968 & 100 \\
\hline
\end{tabular}

Laparotomy was the main route $(86.05 \%)$ of hysterectomies followed by vaginal route $(10.02 \%)$ and laparoscopic route $(3.92 \%)$

injuries $0.82 \%$ ( 8 cases), ureteral injuries $0.72 \%$ ( 7 cases) digestive wound $0.10 \%$ ( 1 case) and death $0.10 \%$ ( 1 case) (Table 6). Postoperative complications included: fever $3.61 \%$ (35 cases), anemia $2.5 \%$ (24 cases), abdominal wall sepsis $0.92 \%$ ( 9 cases), hemoperitoneum $0.10 \%$ ( 1 case) and death $0.10 \%$ ( 1 case). Intra and post operative complications observed were significantly higher following laparotomy than the vaginal route and laparoscopy $(\mathrm{p}=0.003)($ Table 7$)$.

\section{Discussion}

\subsection{Age}

Our mean age is comparable to that reported by Bambo et al. in Congo (42.7 years), Razafindrabe et al. in Madagascar (42.5 years) and Kouam et al. in Cameroon (43.2 years) [3] [6] and [7]. Like Bambo et al. in Congo [3], our population is still influenced by herbal medicine, even in cases of symptomatic fibroid [8] [9] [10] and [11]. This can last for several years, therefore delaying the surgical treatment of benign lesions like uterine myomas at age of 40 or more.

\subsection{Frequency}

Matanga et al. and Egbe et al. reported a frequency of hysterectomy of $14.54 \%$ at the DGH in 2010 [9] [12]. This implies that the practice of hysterectomy has 
Table 5. Surgical methods and Hospital Stay.

\begin{tabular}{cc}
\hline Surgical methods & Average length of stay \\
\hline Laparotomy & $6.07 \pm 1.92$ \\
Vaginal route & $3 \pm 1.09$ \\
Laparoscopy & $3.6 \pm 1.04$ \\
\hline
\end{tabular}

Mean hospital stay was $6.07 \pm 1.92$ days with a minimum of 3 and a maximum of 10 days. The majority of patients $(75.6 \%)$ spent 5 to 7 days postoperatively. Of the first three routes, hospital stay was longer for abdominal hysterectomy with a significant difference $(\mathrm{p}=0.00023)$.

Table 6. Surgical methods and intraoperative complications $(\mathrm{n}=34)$.

\begin{tabular}{ccccc}
\hline \multirow{2}{*}{$\begin{array}{c}\text { Intraoperative } \\
\text { complications }\end{array}$} & \multicolumn{3}{c}{ Surgical methods } & \multirow{2}{*}{ Total } \\
\cline { 2 - 4 } & laparotomy & Vaginal route & Laparoscopy & \\
\hline Hemorrhage & 16 & 1 & 0 & 17 \\
Bladder sores & 8 & 0 & 0 & 8 \\
Ureteral wounds & 7 & 0 & 0 & 7 \\
Digestive wounds & 1 & 0 & 0 & 1 \\
Death & 1 & 0 & 0 & 1 \\
Total & 33 & 1 & 0 & 34 \\
\hline
\end{tabular}

Hemorrhage (12) was the most common cause of intraoperative complications. Followed by vesical wounds (1) and digestive wounds. And these complications are most found when using the high way.

Table 7. Surgical methods and postoperative complications $(n=72)$.

\begin{tabular}{ccccc}
\hline \multirow{2}{*}{$\begin{array}{c}\text { Post operative } \\
\text { complications }\end{array}$} & \multicolumn{3}{c}{ Surgical methods } & \multirow{2}{*}{ Total } \\
\cline { 2 - 4 } & Laparotomy & Vaginal route & Laparoscopy & \\
\hline Fever & 34 & 1 & 0 & 35 \\
Anemia & 23 & 2 & 1 & 26 \\
Abdominal wall sepsis & 9 & 0 & 0 & 9 \\
Haemoperitoneum & 0 & 0 & 1 & 1 \\
Death & 1 & 0 & 0 & 1 \\
Total & 67 & 3 & 2 & 72 \\
\hline
\end{tabular}

Fever and anemia were the postoperative complication found in the three pathways. Postoperative complications after laparotomy were greater than those observed vaginally and laparoscopically significantly ( $\mathrm{p}=$ $0.003)$.

remained constant, in the service of Obstetrics and Gynecology of the DGH. Our frequency is higher than that found at $\mathrm{CHU}$ of Yaoundé, 9.33\% and $\mathrm{CHU}$ of Brazzaville, 6.6\% [3] and [7].

\subsection{Indications}

The main indications of the hysterectomies were symptomatic fibroids in $64.15 \%$ of cases. This rate is close to $64.86 \%$ found by Kouam et al. and $63.9 \%$ of Buambo et al. [3] [7]. This is in phase with literature, which ranks symptomatic uterine fibroids as the principal indication of hysterectomy [10] [11] [13] [14], 
and [15]. A study carried out by Leveque et al. in France, had revealed the predominance of the benign uterine pathology in the order of $70 \%$ amongst the gynaecological indications of hysterectomies [16]. The high rate of fibroids in our study is justified by the high prevalence of this pathology in the female black race [6] [17].

Obstetrical indications represented $2.62 \%$ of cases of hysterectomies in our Hospital and were mainly done for life saving hemostatic reasons.

\subsection{Surgical Methods}

The analysis of postoperative notes identified 234 cases (33.19\%) of abdominal hysterectomies which could have benefited from the vaginal route or laparoscopy. Presently, most data strongly suggest a strong morbidity linked to abdominal hysterectomy which is not the case for minimally invasive techniques which include the vaginal routes and laparoscopies [18] [19] [20] and [21]. Consequently, the tendency now is preference of minimally invasive techniques of hysterectomy, over abdominal hysterectomy [20] in developed countries. We attribute this low index of laparoscopic surgery to the fact that not all the gynaecologists are trained to the technique in one hand and the members of the team like theatre nurses, anaesthetists trained to laparoscopy are lacking. The calculated technical index of hysterectomy in our service was 12.9\% in 2017 [21] close to the 19\% found by gynaecologists of the service of Maha Alkhadury et al. in the Middle East [22] [23], lower than 30\% - 60\% found by Laberge and Singh in Quebec [24] and 90\% in France [25].

\subsection{Length of Hospital Stay}

Our lengths of hospital stay are short for the vaginal routes and laparoscopy. Thanks to a good learning curve and a better control of post-operative pain, the vaginal and laparoscopic methods can reduce the hospital stay to shorter than 24 hours and consequently: reduce the costs of hospitalisation, favouring a rapid healing and early recovery of the patient's societal activities [22] [26] [27] and [28].

\subsection{Complications}

Hemorrhagic complications in our study are explained by hysterectomies done on large polymyomatous uterus, likely in the presence of adhesions, as sequelae of chronic pelvic inflammatory disease [29]. Half of the urinary injuries occurred during debulking surgery for ovarian cancer and during radical hysterectomies and lmphadenectomy for cervical cancer. Post-laparotomy fevers are explained essentially by the large cruentous surfaces, necrosed tissues and residual bleeding (which is less likely with minimally invasive surgery), sources of release of pyrogens [22] [30] [31]. The maternal death observed in our study was due to a complication of septic abortion, despite the successful hysterectomy. Our complications are similar to those observed in literature [3] [7] [31] and [32]. 


\section{Conclusion}

The frequency of hysterectomy is $14.21 \%$. Uterine fibroids, gynaecological cancer and cervical dysplasia are the main indications. Intra-operative haemorrhage, bladder and ureteral injuries are the major complications. There is a longer hospital stay and a higher rate of complications following laparotomy than minimally invasive methods, in our context where the technical index of hysterectomies is low. The increase in the practice of the vaginal and laparoscopic methods through reinforcement of abilities could contribute to reducing the peri- and post-operative complication as well as hospital stay.

\section{Study Limitations}

This study was retrospective with 39 out of 1007 files not included because of missing data; this can create an important bias in the analysis of data.

Furthermore, other important aspects of the technical index like the specific training of gynaecologists in areas like minimally invasive surgery, vaginal hysterectomy or other conservative surgical management of postpartum haemorrhage couldn't be assessed.

\section{Authors' Contribution}

Théophile Nana Njamen and Robert Tchounzou designed the study and wrote the manuscript. Fulbert Nkwele Mangala, Adamo Bongoe, Fidelia Mbi Kobenge participated in patients' recruitment and manuscript revision. All the other authors revised the manuscript.

All the authors read and approved the final version of the manuscript.

\section{Conflicts of Interest}

The authors declare no conflicts of interest regarding the publication of this paper.

\section{References}

[1] Wu, J.M., Wechter, M.E., Eller, E.J., Nguyen, T.V. and Visco, A.G. (2007) Hysterectomy Rate in the United States, 2003. Obstetrics \& Gynecology, 110, 1091-1095. https://doi.org/10.1097/01.AOG.0000285997.38553.4b

[2] Belley, P.E., Mboudou, E., Nana, N.T., Egbe, O.T., Doh, A.S., et al. (2009) L'hystérectomie totale par voie coelioscopique: L'expérience de l'Hôpital Général de Douala, Cameroun. Clinics in Mother and Child Health, 6, 1135-1138.

[3] Buambo-Bamanga, S.F., Moke, P.O., Moussavou, R.D. and Ekoundzola, J.R. (2009) Hystérectomie d'indication gynécologique au Centre Hospitalier et Universitaire de Brazzaville. Clinics in Mother and Child Health, 6, 1113-1116.

[4] Reich, H., Decaprio, J. and McGlynn, F. (1989) Laparoscopic Hysterectomy. Journal of Gynecologic Surgery, 5, 213-216. https://doi.org/10.1089/gyn.1989.5.213

[5] Malzoni, M., Tinelli, R., Cosentino, F., Perone, C., Rasile, M., Iuzzolino, D., et al. (2009) Total Laparoscopic Hysterectomy versus Abdominal Hysterectomy with Lymphadenectomy in Early Endometrial Cancer: A Prospective Randomised Trial. 
Gynecologic Oncology, 112, 126-133. https://doi.org/10.1016/j.ygyno.2008.08.019

[6] Razafindrabe, J.A., Rabarvaona, M., Rakotoarisoa, B., Randriamaro, B. and Rajaonarivony, T. (2002) Les raisons de l'hystérectomie dans un service de gynécologie obstétrique. Médecine d Afrique Noire, 49, 167-168.

[7] Kouam, L., Kongnyuye, J., Ngassa, P., Fomulu, N., Wamba, M.T. and Doh, A.S. (2005) Hysterectomy: A 12 Year Retrospective Review in the Yaoundé University Teaching Hospital. Clinics in Mother and Child Health, 2, 347-350.

[8] Nsagha, D.S., Ayima, C.W., Nana-Njamen, T. and Assob, J.C.N. (2020) The Role of Traditional Complementary/ Alternative Medicine in Primary Healthcare, Ajunct to Universal Health Coverage in Cameroon: A Review of the Literature. American Journal of Epidemiology and Infectious Disease, 8, 37-47.

[9] Matanga, N.N.T. and Belley, P.E. (2013) Hystérectomies à l'Hôpital Général de Douala: Aspects épidémiologiques et cliniques. Thèse de médecine soutenue en 2013 Faculté de Medecine et des Sciences Biomédicales, Université de Yaoundé I, Cameroun.

[10] Kramer, M.G. and Reiter, R.C. (1997) Hysterectomy: Indications, Alternatives and Predictor. American Academy of Family Physicians, 55, 827-834.

[11] Vessey, M.P., Villard-Mackintosh, L., Mc person, K., Coulter, A. and Yeate, D. (1992) The Epidemiology of Hysterectomy Finding in a Large Cohort Study. BJOG: An International Journal of Obstetrics \& Gynaecology, 99, 402-407. https://doi.org/10.1111/j.1471-0528.1992.tb13758.x

[12] Egbe, T.O., Kobenge, F.M., Arlette, M.M.J., Egbe, E.-N., Nyemb, J.E. and Mbu, R.E. (2018) Prevalence and Outcome of Hysterectomy at the Douala General Hospital, Cameroon. A Cross Sectional Study. International Journal of Surgery and Practice, 5, Article No. 902.

[13] Lepine, L.A., Hillis, S.D., Marchbanks, P.A., Koonin, L.M., Morrow, B., Kieke, B.A. and Wilkox, L.S. (1997) Hysterectomy Surveillance-USA, 1980-1993. Morbidity and Mortality Weekly Report. Surveillance Summaries, 46, 1-15.

[14] Chryssikopoulos, A. and Loghis, C. (1986) Indications and Results of Total Hysterectomy. International Surgery, 71, 188-194.

[15] Khan, A.T., Shemar, M. and Gupta, J.K. (2014) Uterine Fibroids: Current Perspective. International Journal of Women's Health, 6, 95-114. https://doi.org/10.2147/IJWH.S51083

[16] Leveque, J., Eon, Y., Collado, B., Foucher, F., Chaperom, D. and Fournierm, A. (2001) Hystérectomie pour pathologie bénigne en région Bretagne: Analyse des pratiques. Journal de Gynécologie Obstétrique et Biologie de la Reproduction, 30, 325-330.

[17] Kjeruff, K.H., Guzinski, G.M., Langenberg, P.W., Stoley, P.D., Stolley, P.D., Moye, N.E. and Kazandjian, V.A. (1993) Hysterectomy and Race. Obstetrics \& Gynecology, 82, 757-764.

[18] Andryjowicz, E. and Wray, T. (2011) Regional Expansion of Minimally Invasive Surgery for Hysterectomy: Implementation and Methodology in a Large Multispecialty Group. Permanente Journal, 15, 42-46. https://doi.org/10.7812/TPP/11-093

[19] Muzii, L., Basile, S., Zupi, E., Marconi, D., Zullo, M.A., Manci, N., et al. (2007) Laparoscopic-Assisted Vaginal Hysterectomy versus Minilaparotomy Hysterectomy: A Prospective, Randomized, Multicenter Study. Journal of Minimally Invasive Gynecology, 14, 610-615. https://doi.org/10.1016/j.jmig.2007.05.012

[20] Garry, R., Fountain, J., Masson, S., Hawe, J., Napp, V., Abbot, J., et al. (2004) The 
Evaluate Study: Two Parallel Randomised Trials, One Comparing Laparoscopic with Abdominal Hysterectomy, and the Other Comparing Laparoscopic with Vaginal Hysterectomy. BMJ, 328, Article No. 129. https://doi.org/10.1136/bmj.37984.623889.F6

[21] Nana Njamen, T., Tchente Nguefack, C., Paul Nkemtendong, T., Kamdem Noumoye, L., Kenfack, B., Njamen Nana, C., Kouam Siegning, L., Mboudou, E., Ngowe Ngowe, M. and Belley Priso, E. (2017) The Trend of the Technicity Index of Hysterectomy in a Tertiary Hospital in Sub-Sahara Africa. International Annals of Medicine, 1.

[22] Bernatchez-Laflamme, S.-M., Bujold, E., Roberge, S. and Laberge, P.Y. (2013) Evolution de l'indice de technicité des hystérectomies au Québec. Journal of Obstetrics and Gynaecology, 35, 144-148. https://doi.org/10.1016/S1701-2163(15)31019-7

[23] Al-Khaduri, M. and Al-Farsi, Y. (2012) Technicity as a Quality Indicator of Excellence in Gynaecology. Sultan Qaboos University Medical Journal, 12, 93-96.

[24] Laberge, P.Y. and Singh, S.S. (2009) Surgical Approach to Hysterectomy: Introducing the Concept of Technicity. Journal of Obstetrics and Gynaecology Canada, 31, 1050-1053. https://doi.org/10.1016/S1701-2163(16)34350-X

[25] Le Point (2010) Hôpitaux le palmarès 2008. http://www.lepoint.fr/html/hopitaux-2008/chirurgiegynecologique.\%20jsp

[26] Stovall, T.G., Summit Jr., R.L., Bran, D.F. and Ling, F.W. (1992) Outpatient Vaginal Hysterectomy: A Pilot Study. Obstetrics \& Gynecology, 80, 145-149.

[27] Levy, B.S., Luciano, D.E. and Emery, L.L. (2005) Outpatient Vaginal Hysterectomy Is Safe for Patients and Reduces Institutional Cost. Journal of Minimally Invasive Gynecology, 12, 494-501. https://doi.org/10.1016/j.jmig.2005.06.015

[28] Evans, D. and Burnett, M. (2018) Audit of Minimally Invasive Hysterectomy Rates: A Canadian Retrospective Cross-Sectional Database Review. Hospital Practices and Research, 3, 1-5. https://doi.org/10.15171/hpr.2018.01

[29] Kasia, J.M., Nana Njamen, T., Messina, R.C., Enama, B.A., Medou, A. and Nguionza, J.M. (2006) Place of Laparoscopic Surgery in the Management of Uterine Leiomyoma in the Cameroonian Woman: A Prospective Study of 80 Cases. Clinics in Mother and Child Health, 3, 567-571.

[30] Blesta, A., Beggreen, E. and Brudvik, P. (2006) Interleukin-1 $\alpha$ and Tumor Necrosis Factors- $\alpha$ Expression during the Early Phases of Orthodontic Tooth Movement in Rats. European Journal of Oral Sciences, 114, 423-429. https://doi.org/10.1111/j.1600-0722.2006.00400.x

[31] Carrilo, E.H., Richason, G.L.E., David, J. and Polk Jr., H.C. (2002) Free Haemoglobin Enhances Tumor Necrosis Factor-(Alpha) Production in Isolated Human Monocytes. Journal of Trauma Injury Infection and Critical Care, 52, 449-452. https://doi.org/10.1097/00005373-200203000-00006

[32] Cravello, L., Bretelle, F., Cohen, D., Roger, V., Giuly, J. and Blanc, B. (2001) L'hystérectomie vaginale: À propos d'une série de 1008 interventions. Gynécologie Obstétrique \& Fertilité, 29, 288-294. https://doi.org/10.1016/S1297-9589(01)00135-7 


\section{Appendix}

XI-1 Data collection form

\section{Hysterectomy in a tertiary hospital in a sub-Saharan setting: A 20-years retrospective review of the indications, types and analysis of technical index}

\section{Data collection sheet}

\section{Identification}

a) Name or ID:

DATE:

b) Age (years): c/ Parity: d/ Residence:

c) Level of education: i/ Primary ii/ Secondary $\quad$ iii/ University

d) Profession:

i) $\mathrm{NE}$

ii) Self-employed

iii) Civil servant

iv) Private salary

v) Student

\section{Past history}
a) Chronic disease:
i) Sickle cell anaemia
ii) Diabetes
iii) HTN (hypertension)
iv) Cancer
v) other
b) Past surgery:
i) No
ii) Yes
Indication and site

c) Tobacco consumption:

i) $\mathrm{No}$

ii) Yes

d) Chronic infection:

i) HIV

ii) Tuberculosis

iii) Hepatitis

\section{Indications of Hysterectomy (stick all correct options)}
a) Uterine myomas
b) Uterine prolapse
c) Uterine rupture
d) Unexplained abnormal uterine bleeding
e) Ovarian cancer
f) Cervical dysplasia
g) Cervical cancer
h) Endometrial cancer:
i) Endometrial atypic hyperplasia
j) Endometrial cancer
k) Post-partum haemorrhage (indicate the cause)

\section{Type of hystetrectomy}
a) Abdominal hysterectomy
b) Vaginal hysterectomy
c) Laparoscopic hysterectomy

\section{Per operatory events}
a) Type of anaesthesia:
i) Local
ii) Spinal
iii) epidural
iv) General
b) Duration of operation:
i) less than $30 \mathrm{~min}$
ii) $30-60 \mathrm{~min}$
iii) $60-120 \mathrm{~min}$
iv) $>120 \mathrm{~min}$
c) Per-op complications:
i) bowel injury
ii) Bladder injury
iii) haemorrhage
iv) Ureteral injury

v) other 


\section{Post-operative events}

a) Duration of hospital stay

b) Haemorrhage

c) Peritonitis

d) Urinary tract infection

e) Surgical site infection

f) Phlebitis

g) Fever

h) Pulmonary embolus

i) Vesico-vaginal fistula 